\title{
Foraging ground fidelity and route-choice tactics of a marine predator: the Antarctic fur seal Arctocephalus gazella
}

\author{
Francesco Bonadonna $^{1, *}$, Mary-Anne Lea ${ }^{2}$, Olivier Dehorter ${ }^{1}$, Christophe Guinet $^{1}$ \\ ${ }^{1}$ Centre d'Etudes Biologiques de Chizé, Centre National de la Recherche Scientifique, 79360 Villiers en Bois, France \\ ${ }^{2}$ Antarctic Wildlife Research Unit, Department of Zoology, University of Tasmania, GPO Box 252-05, Hobart, Tasmania 7001, \\ Australia
}

\begin{abstract}
This study examins the intra- and inter-individual changes in the foraging route-choice behaviour of 45 female Antarctic fur seals Arctocephalus gazella breeding at the Cap Noir colony in the Kerguelen Archipelago, southern Indian Ocean. Satellite transmitters were used to track seals during one or more consecutive foraging trips in 3 consecutive austral summers (1998 to 2000). In all years of study the seals showed a 'colony-preferred direction', concentrating their trips at sea in a $140^{\circ}$ arc east of Kerguelen, indicating a preferred area for foraging. Within this area, lactating females travelled in 1 of 2 main directions: north east toward the edge of the Kerguelen plateau; and less commonly, east/south east. Each direction led seals to sub-areas characterised by different bathymetric features where animals appeared to use different tactics to search for food patches. Moreover, a fidelity index incorporating the mean direction of successive trips and the colony preferred direction indicated the existence of an individual directional fidelity. The organisation of foraging trips suggests 2 levels of learning by seals: a colony memory of the main foraging zone and an individual memory of profitable patches that are exploited by the same individual during successive trips.
\end{abstract}

KEY WORDS: Antarctic fur seal $\cdot$ Satellite transmitter $\cdot$ Foraging trip $\cdot$ Kerguelen Resale or republication not permitted without written consent of the publisher

\section{INTRODUCTION}

During the breeding season, most of marine predators face the problem of obtaining food for themselves and their progeny. Commuting between colonies and feeding areas imposes high energy costs on predators because of the high nutritional and energetic needs of their developing young. Furthermore, searching behaviour adopted by parents is typically spatially limited. Adults with young cannot range as far as nonbreeding individuals as they are temporally limited to avoid offspring starvation. On a large scale in the marine ecosystem, prey may be aggregated within

*E-mail: francesco.bonadonna@cefe.cnrs-mop.fr highly predictable regions with favourable environmental qualities such as frontal structures or upwelling zones. On a smaller scale, prey may form dense, less predictable schools as a predator avoidance response (Fauchald et al. 2000). Consequently, marine predators should concentrate their foraging effort in feeding areas close to their colonies and inside these areas seek and exploit prey patches with high return.

The existence of highly predictable suitable foraging areas could facilitate predator exploitation since individuals from a colony could learn their location and repeatedly focus their activity here. Predators can search actively for food patches inside these large foraging areas. To increase search performance, predators, in the short term, could learn where the best patches are located in the feeding area being exploited. This infor- 
mation could improve their efficiency in relocating patches without wasting time searching and sampling other patches. For example, after a profitable trip predators could learn the position of the patch and return to it on the successive trip. The more learnt, the less time spent searching and sampling.

Antarctic fur seals Arctocephalus gazella are top marine predators and, as with all otariids, commute between their colonies and feeding areas during the pup-rearing period (Gentry \& Kooyman 1986). Consequently, Antarctic fur seals must deal with the problem of finding food. Although diving behaviour and foraging effort of this species at sea have been studied extensively in South Georgia (Costa et al. 1989, Boyd et al. 1991, Boyd \& Croxall 1992, Boyd et al. 1994, Arnould et al. 1996, Boyd 1996), little is known about dispersal patterns while seals are foraging at sea (Boyd et al. 1998, Bonadonna et al. 2000). Antarctic fur seals breeding in South Georgia appear to utilise the same area over 2 consecutive years, and in the same breeding season lactating females head in the same direction over 2 consecutive trips (Boyd et al. 1998, Boyd 1999). This tendency can also be seen in the northern fur seal Callorinus ursinus (Loughlin et al. 1987). However, in the case of the South Georgian fur seals, the fidelity to the same direction over consecutive trips could be an artefact of the narrow sector in front of the colony $\left(<60^{\circ}\right)$ exploited by the population during foraging trips, and individuals could know merely the position of the highly predictable region.

A previous study showed that Antarctic fur seals foraging in Kerguelen headed in a generally preferred mean direction from the colony (Bonadonna et al. 2000), although on a finer scale 2 foraging tactics were apparent. Each tactic was apparently characterised by a particular direction, leading seals to forage in areas with different bathymetric features. In the first tactic, seals took short routes heading north-east while the second tactic was characterised by long looping trips heading mostly east/south-east and leading seals further from the colony. The lack of repeated data on the same individuals, however, made it impossible to distinguish whether individuals consistently followed one tactic or modified their behaviour as a consequence of experience gained during earlier trips. Thus, it was difficult to verify whether these tactics could be considered as part of a strategy or not.

Improving our knowledge of route-choice behaviour could be the key to understanding how females can optimise foraging behaviour. Distinguishing behavioural differences between individuals and differences in behaviour of one individual at different times or under different conditions is an important issue in understanding the foraging plasticity and efficiency of these top predators. To clarify the question of intra- versus inter-individual variation and factors influencing route choice, we analysed the foraging tracks obtained by satellite tracking of lactating Antarctic fur seals from the Kerguelen Archipelago in the austral summers of 1998-99 and 1999-2000 and compared them with results obtained in the austral summer 1997-98 (Bonadonna et al. 2000).

\section{MATERIALS AND METHODS}

Study animals and attachment of devices. The study took place in the Kerguelen Archipelago, southern Indian Ocean during the austral summers 1997-98 (February and March), 1998-99 (December to March) and 1999-2000 (December to March), hereafter referred to as '1998', '1999' and '2000'. The study animals were lactating Antarctic fur seals in the colony breeding at Cap Noir $\left(49^{\circ} 07^{\prime} \mathrm{S}, 70^{\circ} 45^{\prime} \mathrm{E}\right)$, located on the north-eastern part of the main island. Individuals were randomly chosen, captured using a hoop net and restrained for up to $20 \mathrm{~min}$ on a restraint board while the devices were attached. The 45 females were marked by bleaching alphanumeric characters on their rump with peroxide hair dye (Clairol Born Blonde, Bristol-Myers Squibb Ltd., West Ryde, Australia).

A time-depth recorder (TDR-Mk5 in 1998; TDR-Mk7 in 1999 and 2000; Wildlife Computers, Woodinville, WA) mounted on a Platform Terminal Transmitter (PTT, Telonics ST10 electronic cast by Sirtrack Ltd, New Zealand or by the authors; $110 \times 42 \times 14 \mathrm{~mm}$, cross-sectional area $5.7 \mathrm{~cm}^{2}$ ) or a single PTT were used to locate individuals at sea via the Argos satellite system (Taillade 1993). The PTT+TDR packages $(110 \times 42$ $\times 25 \mathrm{~mm}, 150 \mathrm{~g}$, cross-sectional area $10.5 \mathrm{~cm}^{2}$ in 1998; $110 \times 42 \times 25 \mathrm{~mm}, 150 \mathrm{~g}$, cross-sectional area $9.8 \mathrm{~cm}^{2}$ in 1999 and 2000) were shaped with nautical putty to decrease water drag, and were used several times each throughout the study. TDRs were programmed to record wet and dry periods, and depth with a pre-calibrated pressure transducer every $5 \mathrm{~s}$. The devices were attached dorsally to each individual on the midline between the scapulae using a quick-setting 2-part Araldite glue (AW 2101; Ciba Specialty Chemicals Holding Inc., Basle, Switzerland).

The colony was checked twice daily for returning seals. The seals were recaptured after one single foraging trip, or after 2 or 3 consecutive trips, and packages were subsequently deployed again on different individuals. In 1998 we recaptured all the seals after one foraging trip. In 1999 and 2000 some seals were recaptured after 2 or 3 consecutive foraging trips. In the case of seals recaptured after one foraging trip, only those with complete tracks for the whole trip were taken into account. 
Data treatment. PTT locations (or fixes), calculated in reference to 3 satellites, are assigned by Argos to 6 classes on the basis of their estimated accuracy. To assess the error incurred by using different classes of fixes, we used locations recorded whilst the seals were known to be in the colony at Cap Noir (Bonadonna et al. 2000). Estimated mean errors $( \pm \mathrm{SD})$ are presented in Table 1. Only class 0, 1, 2 and 3 locations were used for reconstructing the tracks of foraging trips (Boyd et al. 1998), as after initial analysis most locations provided by classes A and B were judged to be clearly inconsistent with locations from other classes. Argos data were plotted using Elsa99 software (release 1.0; Soft \& Technique Informatique, Beauzelle, France) in conjunction with depth-contour lines from the GEBCO Digital Atlas (release 2, sheet 97.3; British Oceanographic Data Centre).

All locations were examined and those fixes that would have required travel velocities greater than $3 \mathrm{~m} \mathrm{~s}^{-1}$ (Bonadonna et al. 2000) between successive fixes were excluded. The mean direction of each complete track was calculated as the mean vector of the bearing of each fix from the colony. The overall mean direction for each year was calculated from the mean directions of individual tracks, considering all single trips and the first trip for seals tracked during consecutive trips. The maximal distance from the colony reached by each seal was calculated using the greatcircle distance formula (Donnay 1997). TDR records were used to establish exact departure and arrival times to estimate foraging-trip duration. A more detailed analysis of diving behaviour will be presented in a separate paper.

Statistical analysis. The Rayleigh test (Batschelet 1981), was used to test randomness in the mean directions of routes, and the Watson-Williams test (Batschelet 1981) was used to compare the overall mean directions of routes between years (Oriana for Windows release 1.06; Kovach Computing Service, Pentraeth, UK). Since the bearings of mean vectors calculated for each track are restricted to a narrow interval $\left(\leq 180^{\circ}\right)$ and do not qualify for a circular variable, we treated them as a linear variable in successive analyses (Batschelet 1981). Spearman rank correlation, Wilcoxon paired test and the Mann-Whitney $U$-test were performed using Systat (release 9 for Windows; SPSS Inc., Chicago, IL).

Considering that female seals from the Cap Noir colony follow a preferred direction during their foraging trips (Bonadonna et al. 2000) we were precluded from using a paired test, which assumes randomness of samples, to compare direction fidelity during succes- sive trips. By using a Wilcoxon paired test we were also unable to distinguish the actual fidelity of 1 individual during 2 successive trips from the preferred direction of the population.

In order to detect such fidelity we defined a fidelity index (FI):

$$
\mathrm{FI}=\left(\hat{T}-T_{1}\right) \times\left(\hat{T}-T_{2}\right)
$$

where $T_{1}$ and $T_{2}$ are the log-transformed mean directions of the first and second trips and $\hat{T}$ is the mean of the log-transformed mean directions of all tracks. Logtransformation of angular data was used to obtain a Gaussian distribution of the mean direction of tracks. FI varies from -20 to 20 (from -90 to $90^{\circ}$ ). The smallest index value (negative) corresponds to 2 successive trips in the opposite direction (low fidelity trips), and the largest corresponds to 2 trips in the same direction and furthest from the preferred population direction (faithful trips). FI $=0$ corresponds to 2 trips in the same direction as the preferred population direction (trips for which the direction fidelity is undetermined). The overall mean direction of tracks is calculated using data from all 3 yr of study.

We tested the null hypothesis that for a seal, the direction of one trip is independent from the direction of the previous trip, but dependent upon the preferred direction of the population. To test the null hypothesis we used a simulation procedure to generate distribution functions. The randomly generated mean directions of 2 successive trips (Resampling stats release 4.2; Resampling Stats Inc., Arlington, VA) were used to calculate a random Fidelity Index (hereafter called FI ${ }_{\mathrm{r}}$ ). 2 types of simulation were performed using $\mathrm{FI}_{\mathrm{r}}$.

In the first simulation of 100000 trials we tested the probability that the mean FI ( $\overline{\mathrm{FI}})$ of the actual number (n) of seals with 2 consecutive trips $(\mathrm{z}),(\mathrm{n}=\mathrm{z})$ could be randomly extracted from a population of mean $\mathrm{FI}_{\mathrm{r}}$ of $\mathrm{z}$ seals. In the second simulation of 15000 trials we obtained the theoretical distribution function of $\mathrm{FI}_{\mathrm{r}}$ and thus the Type I probability for each actual individual. These individual probabilities were combined according to the 'combining probability' procedure (Sokal \& Rohlf 1981). 


\section{RESULTS}

The number of tracks obtained in the 3 yr study at Cap Noir are summarised in Table 2. Incomplete tracks occur where the PTT ceased emitting a signal after the beginning of the trip. TDRs recorded all diving activity along the foraging route and the arrival and departure times of seals (both accurate to $5 \mathrm{~s}$ ). In some cases the exact arrival and departure times were not known (Mk7 failure of full memory $\mathrm{n}=9$; PTT only $\mathrm{n}=3$ and the package lost at sea after one trip, $n=1$ ) and were estimated by daily checking of the colony to assess the presence or absence of the animals (accurate to $0.5 \mathrm{~d}$ ).

\section{Single trips}

Plots of fixes and circular diagrams for seal tracks are shown in Fig. 1 and the corresponding statistics in Table 3 . The mean direction for each of the 11 routes in 1998 fell mainly in an arc of a circle between 49 and $127^{\circ}$ (mean vector length $=0.8$; direction $83^{\circ}$; Rayleigh test $\mathrm{p}<0.001)$. There was no correlation between the greatest distance reached from the colony and direction taken (Spearman's $\mathrm{r}_{\mathrm{s}}=0.254, \mathrm{n}=11, \mathrm{p}>0.05$ ), though seals heading south/south-east tended to have longer foraging trips.

A similar situation to that obtained in 1998 occurred in 1999. Globally, the mean direction of each route for the 19 seals in 1999 fell in an arc of a circle between 48 and $113^{\circ}$ (mean vector length $=0.9$; direction $75^{\circ}$; Rayleigh test $p<0.001$ ). A Watson-Williams test showed no differences in the mean vectors of foraging trips in 1998 and 1999 ( $f=0.409, \mathrm{p}=0.528$ ). Contrary to 1998, the greatest distance reached from the colony and the mean direction for each route were positively correlated (Spearman's $\mathrm{r}_{\mathrm{s}}=0.582, \mathrm{n}=19, \mathrm{p}<0.01$ ), indicating that most seals heading east/south-east travelled further.

In 2000, seals dispersed in a greater arc of a circle, between 40 and $150^{\circ}$ (mean vector length $=0.87$; direction $88^{\circ}$; Rayleigh test $\mathrm{p}<0.001$ ), and seals heading north-east travelled further from the colony compared to seals travelling in the same direction during 1998

Table 2. Arctocephalus gazella. Summary of tracks obtained during the 3 yr study at Cap Noir. In parentheses: number of seals with incomplete second tracks

\begin{tabular}{|lccc|}
\hline Yr & $\begin{array}{c}1 \text { complete } \\
\text { trip }\end{array}$ & $\begin{array}{c}2 \text { consecutive } \\
\text { trips }\end{array}$ & $\begin{array}{c}3 \text { consecutive } \\
\text { trips }\end{array}$ \\
\hline 1998 & 11 & - & - \\
1999 & 15 & $4(1)$ & - \\
2000 & 12 & $6(2)$ & 1 \\
\hline
\end{tabular}

Table 3. Arctocephalus gazella. Statistics for seals tracked for one single trip. Max distance $=$ maximum distance from the colony reached by a seal

\begin{tabular}{|c|c|c|c|c|c|}
\hline Seal & $\begin{array}{l}\text { Austral } \\
\text { summer }\end{array}$ & $\begin{array}{c}\text { Departure } \\
\text { date }\end{array}$ & $\begin{array}{l}\text { Time } \\
\text { at sea } \\
\text { (d) }\end{array}$ & $\begin{array}{c}\text { Max } \\
\text { distance } \\
(\mathrm{km})\end{array}$ & $\begin{array}{c}\text { Mean } \\
\text { direction } \\
\left({ }^{\circ}\right)\end{array}$ \\
\hline ot $0^{\mathrm{a}}$ & 1998 & 06 Feb 98 & 7.2 & 98 & 48 \\
\hline ot1 & 1998 & 05 Feb 98 & 5.7 & 97 & 52 \\
\hline ot $2^{\mathrm{a}}$ & 1998 & 06 Feb 98 & 8 & 152 & 172 \\
\hline ot3 & 1998 & 07 Feb 98 & 2.9 & 88 & 106 \\
\hline ot $42^{\mathrm{a}}$ & 1998 & 11 Feb 98 & 17 & 547 & 77 \\
\hline ot $43^{a}$ & 1998 & 12 Feb 98 & 5 & 111 & 51 \\
\hline ot4 $7^{a}$ & 1998 & 14 Feb 98 & 7.9 & 243 & 110 \\
\hline ot51 & 1998 & 15 Feb 98 & 3.8 & 68 & 78 \\
\hline ot52 ${ }^{\mathrm{a}}$ & 1998 & 18 Feb 98 & 6.7 & 118 & 127 \\
\hline ot55 & 1998 & 20 Feb 98 & 6.9 & 145 & 55 \\
\hline ot57 & 1998 & 25 Feb 98 & 5.9 & 93 & 63 \\
\hline L1 & 1999 & 19 Jan 99 & 4.2 & 86 & 95 \\
\hline L3 & 1999 & 21 Jan 99 & 10 & 308 & 113 \\
\hline L8 & 1999 & 10 Feb 99 & 4.9 & 103 & 67 \\
\hline L9 & 1999 & 12 Feb 99 & 9.1 & 95 & 77 \\
\hline $\mathrm{T} 1$ & 1999 & 18 Dec 98 & 7.9 & 160 & 74 \\
\hline $\mathrm{T} 2$ & 1999 & 18 Dec 98 & 8.6 & 271 & 81 \\
\hline $\mathrm{T} 7$ & 1999 & 29 Dec 98 & 3.9 & 74 & 76 \\
\hline $\mathrm{T} 8$ & 1999 & 29 Dec 98 & 5.1 & 81 & 58 \\
\hline $\mathrm{T} 4^{\mathrm{a}}$ & 1999 & 21 Dec 98 & 11 & 265 & 68 \\
\hline $\mathrm{L} 6^{\mathrm{a}}$ & 1999 & 06 Feb 99 & 9 & 310 & 101 \\
\hline $\mathrm{B} 121^{\mathrm{b}}$ & 1999 & 07 Feb 99 & 4 & 65 & 54 \\
\hline $\mathrm{RR} 24^{\mathrm{b}}$ & 1999 & 12 Feb 99 & 10 & 283 & 95 \\
\hline ot1 & 1999 & 31 Jan 99 & 7 & 190 & 101 \\
\hline ot55 & 1999 & 02 Feb 99 & 5.9 & 144 & 75 \\
\hline ot57 & 1999 & 05 Feb 99 & 4 & 98 & 61 \\
\hline $\mathrm{F} 1^{\mathrm{b}}$ & 2000 & 24 Dec 99 & 8.3 & 164 & 57 \\
\hline $\mathrm{H} 2$ & 2000 & 15 Jan 00 & 6.8 & 230 & 92 \\
\hline P1 & 2000 & 16 Dec 99 & 6.2 & 166 & 66 \\
\hline $\mathrm{P} 2^{\mathrm{a}}$ & 2000 & 17 Dec 99 & 5.3 & 195 & 85 \\
\hline P3 & 2000 & 16 Dec 99 & 6.2 & 183 & 71 \\
\hline P4 & 2000 & 21 Dec 99 & 5.5 & 126 & 79 \\
\hline P6 & 2000 & 17 Dec 99 & 4.4 & 126 & 98 \\
\hline P8 & 2000 & 22 Dec 99 & 10.3 & 243 & 61 \\
\hline P9 & 2000 & 22 Dec 99 & 5.4 & 165 & 99 \\
\hline T3 & 2000 & 07 Jan 00 & 2.8 & 66 & 70 \\
\hline H5 & 2000 & 30 Jan 00 & 6.2 & 186 & 142 \\
\hline $\mathrm{S} 4$ & 2000 & 24 Feb 00 & 10.4 & 328 & 123 \\
\hline
\end{tabular}

and 1999 (Table3). However, the mean vector for 2000 is not statistically different when compared to the mean vectors of preceding years (Watson-Williams test 2000 vs $1998, f=0.162, \mathrm{p}=0.691 ; 2000$ vs $1999, f=$ $2.136, \mathrm{p}=0.153$ ). A Mann-Whitney $U$-test on maximal distance from the colony reached by seals heading between 30 and $90^{\circ}$ in 1998, 1999 and 2000 is not significant. During the 2000 austral summer, most seals heading east/south-east travelled further than seals heading north-east since the greatest distance reached from the colony and the mean direction for each route were positively correlated (Spearman's $\mathrm{r}_{\mathrm{s}}=0.516, \mathrm{n}=$ 


\section{8}
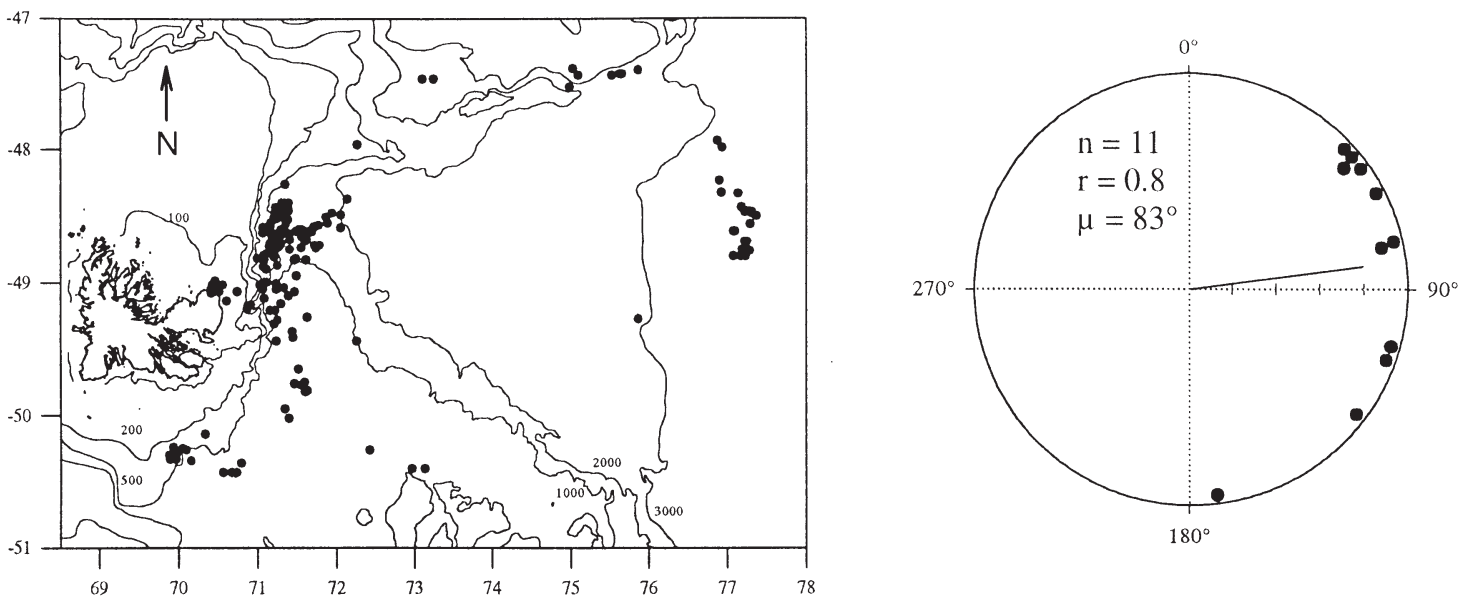

\section{9}
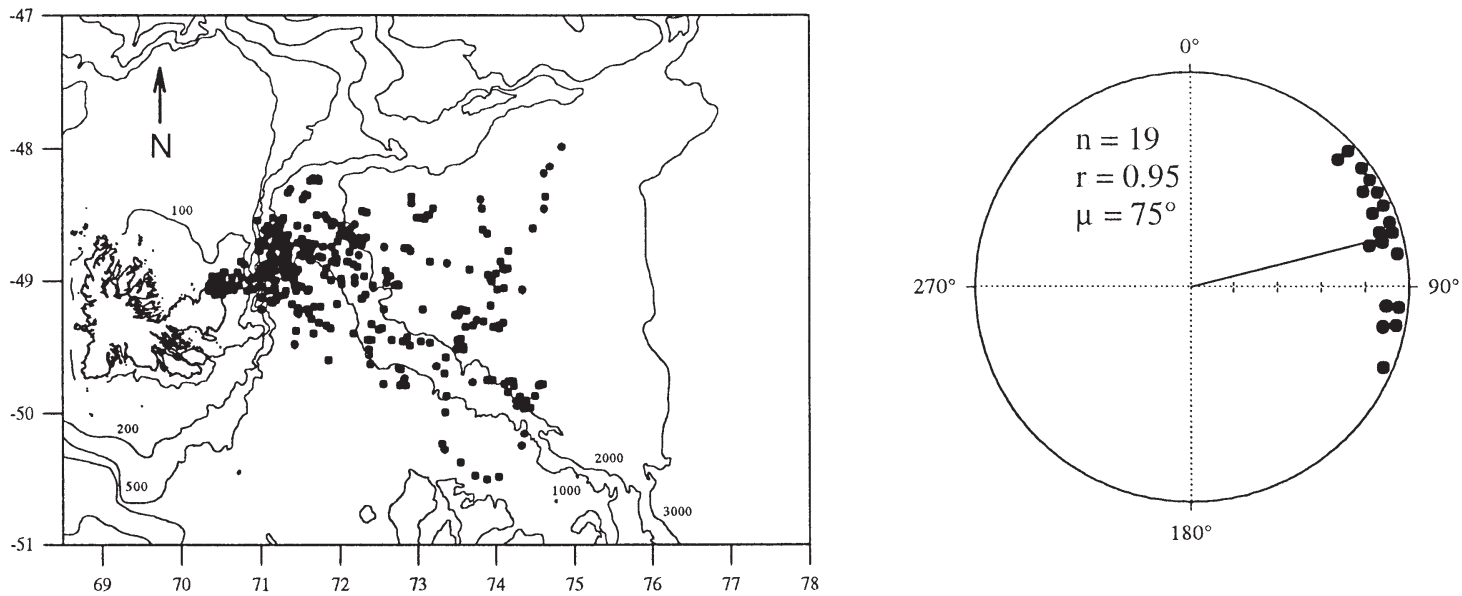

2000
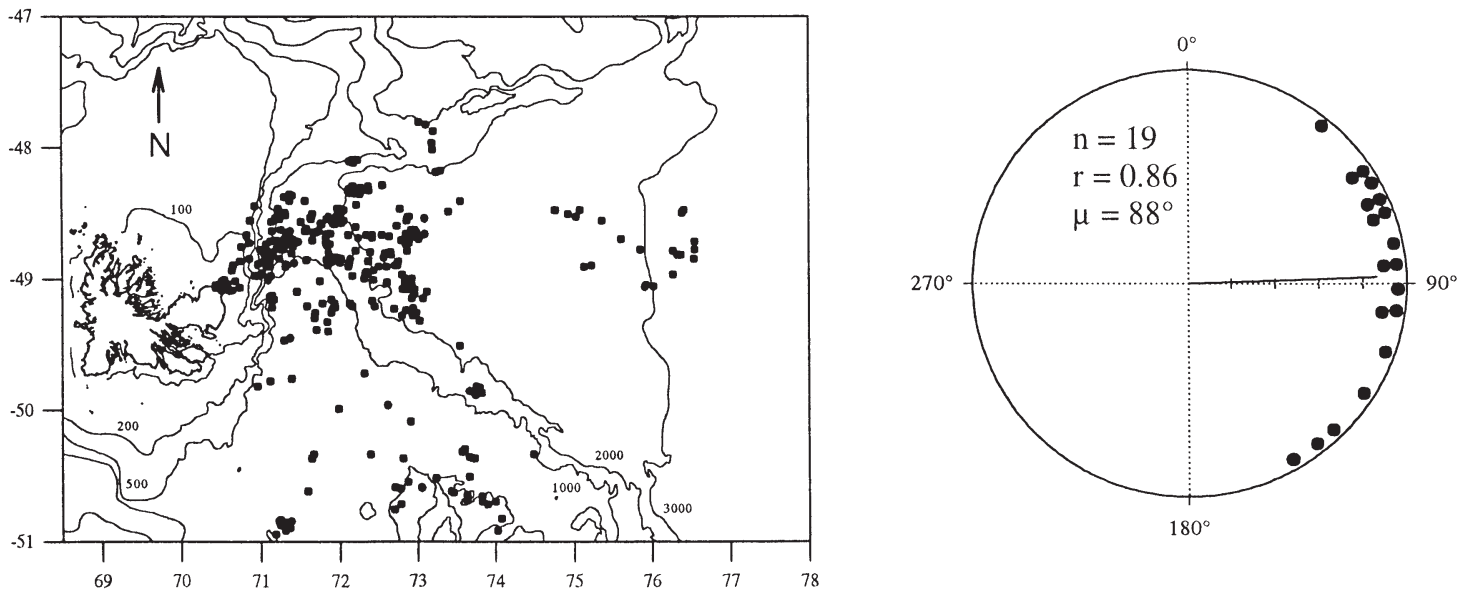

Fig. 1. Arctocephalus gazella. Distribution at sea of satellite locations for tracked seals and circular diagrams representing the distribution of the mean bearing of foraging routes. Sea depth $(\mathrm{m})$ is indicated by isometric lines; $1^{\circ} l a t i t u d e=111 \mathrm{~km}$; $1^{\circ}$ longitude $=72.5 \mathrm{~km}$. r: mean vector length; $\mu$ : mean vector direction 

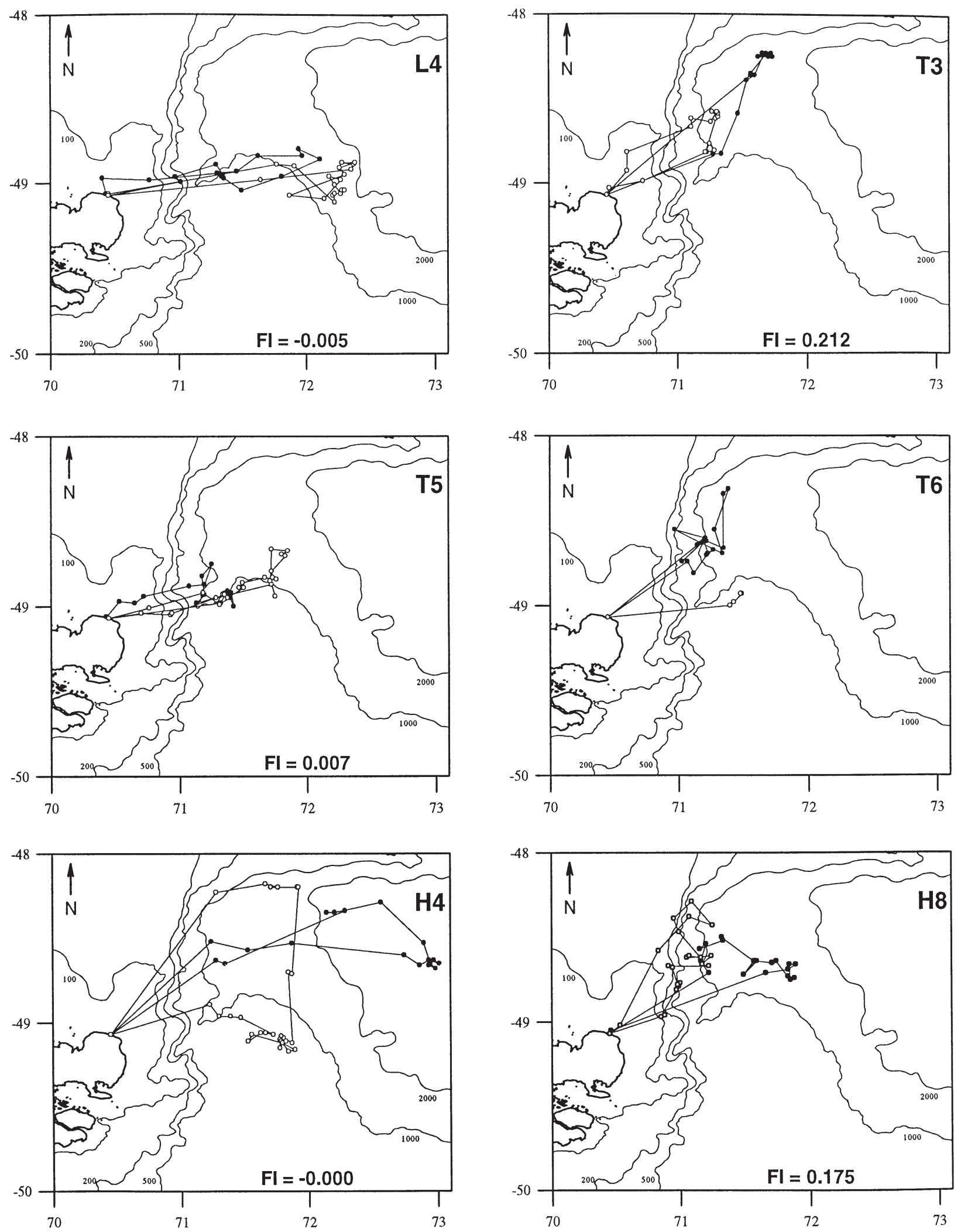

Fig. 2. Arctocephalus gazella. Foraging tracks of 6 seals equipped with PTT during consecutive trips. $(\bullet)$ first trip, (०) second trip, FI: Fidelity Index. Alphanumeric marks in the top right-hand corner as in Table 4. Other explanations as in Fig. 1 
19, $\mathrm{p}<0.05)$. A rank-correlation on pooled data from 1998, 1999 and 2000 showed a positive correlation between the greatest distance reached from the colony and direction taken (Spearman's $r_{s}=0.369$, $\mathrm{n}=30, \mathrm{p}<0.01)$.

\section{Consecutive trips}

The consecutive paths of seals tracked in $1999(\mathrm{n}=4)$ and $2000(n=7)$ are shown in Figs 2 \& 3, while data relevant to these routes are given in Table 4 . The second track of seal S1 (austral summer 2000; Fig. 3) was not complete but the mean vector was calculated and compared to that of the first trip since the high concentration of fixes before the PTT failed indicated that the seal was at the feeding area (Bonadonna et al. 2000). Also, a rectilinear inbound trip, as observed in the preceding trip, would not have changed the mean direction.

A qualitative visual inspection of tracks suggests that seals have a directional fidelity in successive trips except for the third trip of seal S3 with respect to preceding ones. Simulation on the mean direction of seals' tracks confirmed this result. Eight seals with 2 consecutive trips and 1 with 3 consecutive trips were considered in statistical analyses. The direction of successive foraging trips $(\overline{\mathrm{FI}})$ of these seals was dependent upon the direction of the previous trip ( $\mathrm{p} \leq$ $0.0007)$ and its positive value $(\overline{F I}=0.142)$ indicates that breeding female seals from Cap Noir tended to travel in the same direction in subsequent foraging trips.

At an individual level, for 2 of the 9 seals (S1 and S3) we can reject the null hypothesis of direction independence between 2 successive trips; their FI indicates fidelity (see Table 4). In addition to this, considering the hypothesis of fidelity, 1-tailed results indicate that 4 seals (T3, H8, S1, S3) travelled in the same direction as their previous trip whilst none of them present a significantly negative FI. By combining probabilities we obtained a 2-tailed probability of $\mathrm{p} \leq 0.047$. By excluding the third trip of seal S3 from the combination of probabilities we obtained a result of $p \leq 0.014$. Thus, globally, females from Cap Noir were faithful to the direction taken in a previous foraging trip during subsequent trips.

In seals performing 2 successive trips in the same direction, the time at sea for the first and second trips is similar (Table 4 ), the difference ranging from 0.1 to $2.4 \mathrm{~d}$. For the same seals, difference in distance from the colony ranges from 16 to $113 \mathrm{~km}$. These differ-

Table 4. Arctocephalus gazella. Statistics for seals tracked for 2 or 3 consecutive trips. Max distance = maximum distance from the colony reached by a seal; FI: Fidelity Index. $\mathrm{p}<0.05$ in bold

\begin{tabular}{|c|c|c|c|c|c|c|c|c|}
\hline Seal & $\begin{array}{l}\text { Austral } \\
\text { summer }\end{array}$ & $\begin{array}{l}\text { Departure } \\
\text { date }\end{array}$ & $\begin{array}{l}\text { Time at sea } \\
\text { (d) }\end{array}$ & $\begin{array}{l}\text { Max distance } \\
(\mathrm{km})\end{array}$ & $\begin{array}{c}\text { Mean direction } \\
\left({ }^{\circ}\right)\end{array}$ & FI & $\begin{array}{l}\text { 2-tailed } \\
\text { probability }\end{array}$ & $\begin{array}{l}\text { 1-tailed } \\
\text { probability }\end{array}$ \\
\hline L4 1st trip & 1999 & 21 Jan 99 & 4.9 & 123 & 72 & \multirow{2}{*}{-0.005} & \multirow{2}{*}{0.9658} & \multirow{2}{*}{0.4829} \\
\hline L4 2nd trip & 1999 & 29 Jan 99 & 6.6 & 142 & 83 & & & \\
\hline T3 1st trip & 1999 & 18 Dec 98 & 6 & 132 & 49 & \multirow{2}{*}{0.212} & \multirow{2}{*}{0.0632} & \multirow{2}{*}{0.0316} \\
\hline T3 2nd trip & 1999 & 25 Dec 98 & 4.7 & 83 & 49 & & & \\
\hline T5 1st trip & 1999 & 27 Dec 98 & 2.6 & 71 & 63 & \multirow{2}{*}{0.007} & \multirow{2}{*}{0.7841} & \multirow{2}{*}{0.3921} \\
\hline T5 2nd trip & 1999 & 31 Dec 98 & 4.3 & 111 & 75 & & & \\
\hline T6 1st trip & 1999 & 29 Dec 98 & 5.7 & 108 & 49 & \multirow[t]{2}{*}{ * } & \multirow[t]{2}{*}{ * } & \multirow[t]{2}{*}{$*$} \\
\hline T6 2nd trip* & 1999 & 05 Jan 99 & 9.7 & 73 & 81 & & & \\
\hline H3 1st trip & 2000 & 29 Jan 00 & 12.3 & 448 & 85 & \multirow{2}{*}{0.014} & \multirow{2}{*}{0.6889} & \multirow{2}{*}{0.3444} \\
\hline H3 2nd trip & 2000 & 14 Feb 00 & 12.4 & 413 & 91 & & & \\
\hline H4 1st trip & 2000 & 30 Jan 00 & 8.9 & 193 & 66 & \multirow{2}{*}{-0.000} & \multirow{2}{*}{0.9277} & \multirow{2}{*}{0.4639} \\
\hline H4 2nd trip & 2000 & 10 Feb 00 & 9.9 & 145 & 78 & & & \\
\hline H6 1st trip & 2000 & 31 Jan 00 & 9.3 & 259 & 110 & \multirow{2}{*}{0.074} & \multirow{2}{*}{0.3009} & \multirow{2}{*}{0.1504} \\
\hline H6 2nd trip & 2000 & 12 Feb 00 & 11.7 & 372 & 96 & & & \\
\hline H7 1st trip & 2000 & 29 Jan 00 & 8.8 & 251 & 136 & \multirow[t]{2}{*}{ * } & \multirow[t]{2}{*}{ * } & \multirow[t]{2}{*}{ * } \\
\hline H7 2nd trip* & 2000 & 09 Feb 00 & 10.3 & 187 & 110 & & & \\
\hline H8 1st trip & 2000 & 31 Jan 00 & 5.5 & 114 & 57 & \multirow{2}{*}{0.175} & \multirow[t]{2}{*}{0.0913} & \multirow[t]{2}{*}{0.0457} \\
\hline H8 2nd trip & 2000 & 07 Feb 00 & 5.7 & 98 & 44 & & & \\
\hline S1 1st trip & 2000 & 12 Feb 00 & 9.2 & 215 & 150 & \multirow{2}{*}{0.451} & \multirow{2}{*}{0.0044} & \multirow{2}{*}{0.0022} \\
\hline S1 2nd trip* & 2000 & 23 Feb 00 & 10.8 & 231 & 154 & & & \\
\hline S3 1st trip & 2000 & 18 Feb 00 & 5.9 & 81 & 40 & 0.347 & & \\
\hline S3 2nd trip & 2000 & 26 Feb 00 & 4.9 & 120 & 46 & \multirow{2}{*}{$\begin{array}{r}0.04 t \\
-0.143\end{array}$} & \multirow{2}{*}{$\begin{array}{l}0.0130 \\
0.1451\end{array}$} & \multirow{2}{*}{$\begin{array}{l}\mathbf{0 . 0 0 0 9} \\
0.0726\end{array}$} \\
\hline S3 3rd trip & 2000 & 03 Mar 00 & 11.8 & 262 & 102 & & & \\
\hline
\end{tabular}



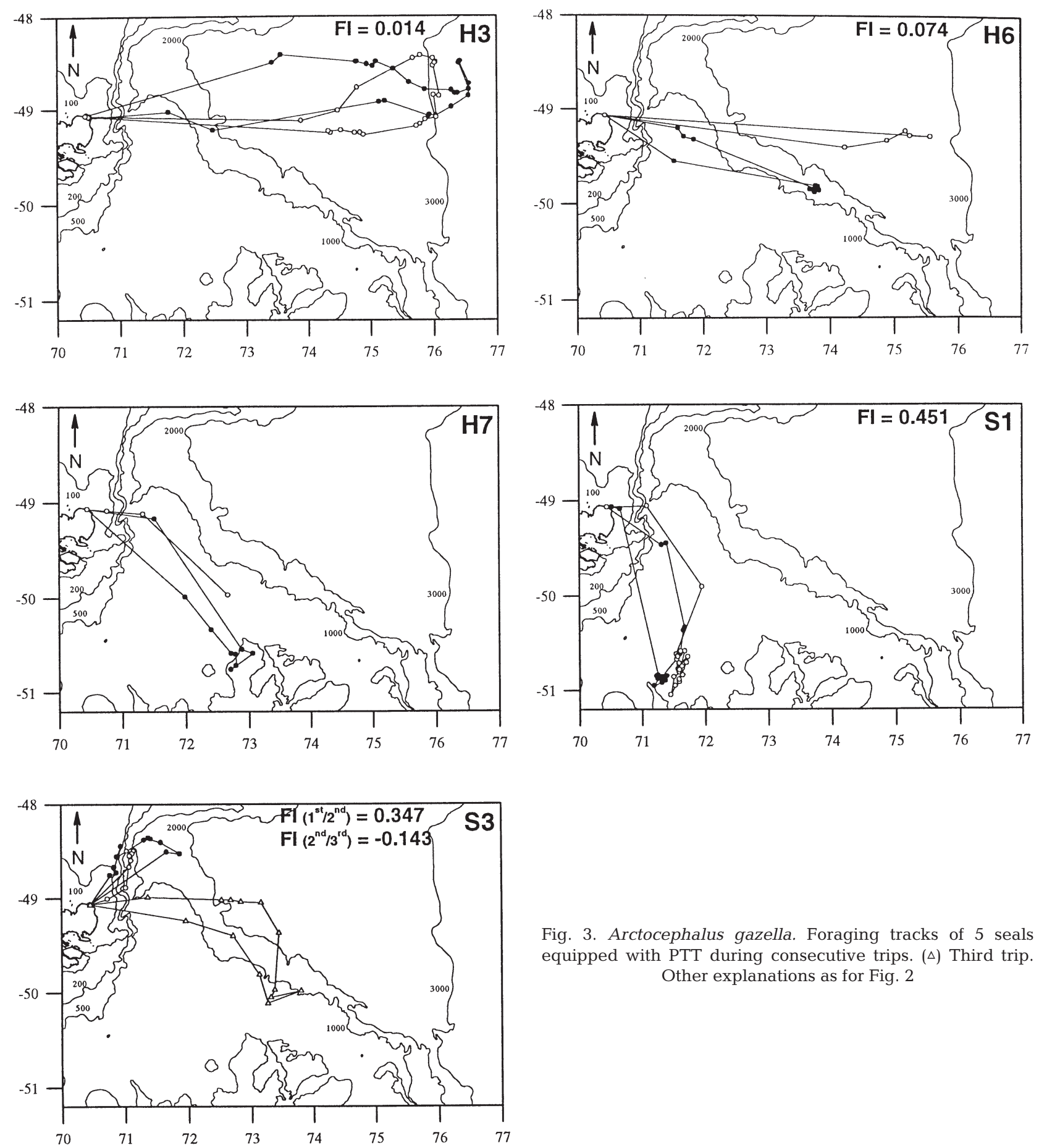

Fig. 3. Arctocephalus gazella. Foraging tracks of 5 seals equipped with PTT during consecutive trips. $(\Delta)$ Third trip. Other explanations as for Fig. 2

ences are not statistically significant (Wilcoxon paired test).

The visual inspection of tracks helps in the case of seals for which we have only an incomplete second track. In the case of seals $\mathrm{H} 7$ and T6 the second trip seemed to follow the same pattern as the previous trip. However, during the second trip female T6 remained at sea longer (Table 4), leading us to suppose she utilised a different foraging trip tactic. On the other hand the third trip of seal S3 appeared to be different (even if not statistically so, Table 4) from the preceding 2 trips, both in terms of the shape, direction and time at sea. This idea is supported by the negative FI, suggesting infidelity with respect to the direction of the preceding trip. 


\section{DISCUSSION}

The use of satellite transmitters in this study highlighted a colony-preferred direction and an individual direction fidelity during feeding movements of female Antarctic fur seals breeding at Cap Noir. In all years of study, seals exhibited similar behavioural patterns. On a large scale, most of the seals travelled eastwards within the same sector in front of the colony: an arc ranging between 40 and $180^{\circ}$ and $300 \mathrm{~km}$ wide, indicating that the animals tended to use the same general area over consecutive years, as observed for Antarctic fur seals in South Georgia (Boyd et al. 1998), and for Subantarctic fur seals Arctocephalus tropicalis on Amsterdam Island (Georges et al. 2000). In fact, the overall mean direction of foraging trips was statistically indistinguishable among years. This sector is well separated from the sector apparently exploited by seals breeding at Iles Nuageuses, $200 \mathrm{~km}$ west of Cap Noir (unpubl. data). This suggests that each colony probably has a preferred foraging area characterised by particular environmental features, such as upwelling zones or frontal structures, meeting the seals' need for abundant prey (Guinet et al. 2001).

On a finer scale, the seals from Cap Noir showed 2 foraging tactics. Each foraging tactic appears to be linked to a specific mean direction taken during the trip. In the first tactic, seals performed short trips heading north-east. This type of track led the animals directly to an area approximately 65 to $200 \mathrm{~km}$ away from the colony, where they concentrated their diving activity during night without moving away from the area during the day (Bonadonna et al. 2000). The second tactic was characterised by long trips heading mostly east/south-east, leading seals approximately 150 to $500 \mathrm{~km}$ from the island. Seals tended to travel during the day when using this second tactic (Bonadonna et al. 2000).

The first tactic was the most common, and the area where the animals concentrated their activity coincides with the outer limits of the Kerguelen Plateau, where ocean depth increases rapidly. The concentration of foraging by Antarctic fur seals at the edge of the continental shelf has also been observed in South Georgia (Boyd et al. 1998). The depth contour most likely coincides with the most suitable prey habitat for the Antarctic fur seal (Guinet et al. 2001), and resulting patches could be more concentrated and consequently easier to find. The fact that seals tended to set out for this relatively narrow foraging zone most of the time could be explained if we suppose that lactating females learned that the area was generally a good feeding area from past experience, it is close to the colony, and could be reached in a short time. Thus, the edge of the continental shelf at Kerguelen probably meets the seals' need to exploit prey patches with high return, close to the colony and only spending a limited time at sea.

The preference for the area to the northeast of Kerguelen does not exclude the possibility that prey is also abundant in other areas, although patches may be less concentrated and further from the colony. Our hypothesis is that seals could use a second tactic to reduce negative effects experienced through interactions with other top marine predators such as reduced prey availability or intra- and interspecific competition. If most of the seals focus their activity at the edge of the continental shelf, the area may become heavily exploited and competition between individuals may increase. For this reason it is a possibility that some animals may choose a different foraging-trip direction, for example, east/southeast, a sector used in all years but requiring longer trips. This sector is exploited by the same species breeding at Heard Island, $500 \mathrm{~km}$ southeast of Kerguelen (Green 1997), indicating that it is a suitable feeding area. It appears to be an extensive area and therefore patches could be widely dispersed. Thus, seals probably need to search for good foraging patches en route (Bonadonna et al. 2000). We can suppose that the generally-preferred foraging area is composed of 2 or more 'sub-areas' characterised by different bathymetric features and different direction from the colony and where seals could adopt different behaviour in the search for food patches (Bonadonna et al. 2000).

On an individual scale, our results show that seals tend to maintain the direction and therefore tactic adopted in the preceding trip. Furthermore, trip duration was similar between the 2 trips, indicating that animals headed directly to 'sub-areas' of previous feeding success (Loughlin et al. 1987, Boyd 1999). Nevertheless, the area where feeding occurred was not necessarily the same. Indeed, although the direction remains similar, the distance from the colony can vary between trips. This leads us to suppose that seals record the direction taken during foraging trips, and take the same direction in successive trips. During the trip they adopt an opportunistic sampling behaviour, stopping where good patches are found. Learning the predictable sub-area direction and not an actual patch position could be profitable, since the position of small scale patches could be unpredictable (Fauchald et al. 2000). This behaviour could be particularly useful when more widespread, and consequently less predictable patches force seals to search longer to find a profitable patch. Thus, learning a direction could improve foraging efficiency, especially for those seals which adopt the second tactic by heading east/southeast. 
Our results also show that the direction of successive foraging trips can vary. A seal can head in the same direction during 2 successive trips and then change direction and tactic (e.g. seal S3, Fig. 3). The reasons for such a shift are not well understood, although we can suppose that it may improve foraging efficiency. For example, an unsuccessful foraging trip could influence the seal to change direction and/or tactic and consequently to search for new food patches. In this case the colony could play the role of an information centre (Ward \& Zahavi 1973), with the directional location of new prey patches being involuntarily exchanged at the colony by returning seals.

In the light of these considerations, we can regard the 2 tactics as part of a strategy where an individual seal could choose, among different options, the most appropriate way to solve its biological problem. Our hypothesis is that the route-choice behaviour of Antarctic fur seals could be driven by 2 levels of learning and foraging efficiency evaluation. On the first level, seals may know where suitable foraging grounds are located with respect to their colony. This main area is probably the nearest highly predictable area with favourable environmental features that meet the seals' prerequisites of patch encounter rate and food quality. Within this area, lactating females could prefer sub-areas characterised by particular features and requiring different exploitation strategies to locate food patches. This choice could be driven by the abundance prey of patches versus inter-individual competition, since resource value decreases with increased competition. In the first tactic, seals exploit good patches, the quality of which could be reduced by inter-individual competition while in the second strategy seals are obliged to travel further and for longer, but reduced competition enhances the quality of patches. This supports the hypothesis of Arnould et al. (1996) who suggested that a seal undertaking short trips expends less time in searching, while seals undertaking long trips expend more time in searching but probably exploit patches of higher quality. On a second level of learning, an individual seal, depending on foraging trip success, could record the direction of good patches and try to find them in a successive trip, or it could change direction and consequently its strategy. If the previous trip has been profitable, this level of learning gives seals the opportunity to return rapidly to previously-exploited patches without wasting time in searching for a new one. On the other hand, the ability to evaluate foraging trip efficiency could enable seals to start a new search or to switch between tactics to optimise the energy intake. This ability of Antarctic fur seals to profit from experience can improve their foraging efficiency by responding appropriately to environmental changes and by capitalising on information gained through the searching and sampling of patches.

Acknowledgements. A Marie Curie Fellowship from the European Community (Fourth Framework Programme, Training and Mobility of Researchers, Contract number ERBFMBICT972614) to F.B. financed this research in part. We are especially indebted to the Institut Français pour la Recherche et Technologie Polaires, which supported this study both financially and logistically. This study was also funded by The Australian Antarctic Scientific Advisory Committee (ASAC Project No. 2128) and the Seaworld Research and Rescue Foundation Inc., Australia. We are grateful to Pierrick Bocher, Laurent Dubroca, Simon Goldsworthy, Jérôme Spaggiari, Sam Thalmann, and the 1998, 1999 and 2000 expeditioners at Kerguelen for their help in the field. Bristol-Myers Squibb generously provided Clairol bleaching products for which we also are very grateful. All the experiments comply with the current laws of the country in which they were performed. The manuscript benefited from the valuable comments of 3 anonymous reviewers.

\section{LITERATURE CITED}

Arnould JPY, Boyd IL, Speakman JR (1996) The relationship between foraging behaviour and energy expenditure in Antarctic fur seals. J Zool (Lond) 239:769-782

Batschelet E (1981) Circular statistics in biology. Academic Press, London

Bonadonna F, Lea MA, Guinet C (2000) Foraging routes of Antarctic fur seal (Arctocephalus gazella) investigated by the concurrent use of satellite tracking and Time Depth Recorder. Polar Biol 23:149-159

Boyd IL (1996) Temporal scales of foraging in a marine predator. Ecology 77:426-434

Boyd IL (1999) Foraging and provisioning in Antarctic fur seals: interannual variability in time-energy budgets. Behav Ecol 10:198-208

Boyd IL, Croxall JP (1992) Diving behaviour of lactating Antarctic fur seals. Can J Zool 70:919-928

Boyd IL, Lunn NJ, Barton T (1991) Time budgets and foraging characteristics of lactating Antarctic fur seals. J Anim Ecol 60:577-592

Boyd IL, Arnould JPY, Barton T, Croxall JP (1994) Foraging behavior of Antarctic fur seals during periods of contrasting prey abundance. J Anim Ecol 63:703-713

Boyd IL, McCafferty DJ, Reid K, Taylor R, Walker TR (1998) Dispersal of male and female Antarctic fur seals (Arctocephalus gazella). Can J Fish Aquat Sci 55:845-852

Costa DP, Croxall JP, Duck CD (1989) Foraging energetics of Antarctic fur seals in relation to changes in prey availability. Ecology 70:596-606

Donnay JP (1997) Cartographie mathématique, série surfaces 2. Université de Liège, Liège

Fauchald P, Erikstad KE, Skarsfjord H (2000) Scaledependent predator-prey interactions: the hierarchical spatial distribution of seabirds and prey. Ecology 81: 773-783

Gentry RL, Kooyman GL (1986) Fur seals, maternal strategies on land and at sea. Princeton University Press, Princeton, NJ

Georges JY, Bonadonna F, Guinet C (2000) Foraging habitat 
and diving activity of lactating Subantarctic fur seals in relation to sea surface temperatures at Amsterdam Island. Mar Ecol Prog Ser 196:291-304

Green K (1997) Diving behaviour of Antarctic fur seals Arctocephalus gazella Peters around Heard Island. In: Hindell $\mathrm{M}$, Kemper $\mathrm{C}$ (eds) Marine mammal research in the southern hemisphere volume I: status, ecology and medicine. Surrey Beatty and Sons, Chipping Norton, p 97-104

Guinet C, Dubroca L, Lea MA, Goldsworthy SD, Cherel Y, Duhamel G, Bonadonna F, Donnay JP (2001) Spatial distribution of foraging in female Antarctic fur seals Arctocephalus gazella in relation to oceanographic variables: a

Editorial responsibility: Otto Kinne (Editor),

Oldendorf/Luhe, Germany scale-dependent approach using geographic information systems. Mar Ecol Prog Ser 219:251-264

Loughlin TR, Bengtson JL, Merrik RL (1987) Characteristics of feeding trips of female northern fur seals. Can J Zool 65: 2079-2084

Sokal RR, Rohlf FG (1981) Biometry. WH Freeman and Company, New York

Taillade M (1993) Trends in satellite-based animal tracking. In: Mancini P, Fioretti S, Cristalli C, Bedini R (eds) Biotelemetry XII. Litografia Felici, Pisa. p 291-297

Ward P, Zahavi A (1973). The importance of certain assemblages of birds as 'information centres' for food finding. Ibis 115:517-534

Submitted: November 9, 2000; Accepted: March 27, 2001 Proofs received from author(s): November 1, 2001 